\title{
Comparative analysis of indirect, direct, and hybrid cryogenic machining of Nimonic C-263 superalloy
}

\author{
Prashant S Jadhav*,** and Chinmaya P Mohanty*,*** \\ * School of Mechanical Engineering (SMEC), Vellore Institute of Technology, Vellore, Tamil Nadu, India \\ ** Department of Mechanical Engineering, Rajarambapu Institute of Technology, Shivaji University, Maharashtra, Kolhapur, India \\ ***Corresponding Author: chinmaymohantymech@gmail.com
}

Submitted : 17/04/2020

Revised :07/10/2020

Accepted : 14/10/2020

\begin{abstract}
Nickel based superalloys have extensive usage in manufacturing of intricate part shapes in gas turbine, aircraft, submarine, and chemical industries owing to their excellent mechanical property and heat resistant abilities. However, machining of such difficult-to-machine alloys up to the desired accuracy and preciseness is a complex task owing to a rapid tool wear and failure. In view of this, the present work proposes an experimental investigation and optimization of process parameters of the cryogenic assisted turning process during machining of Nimonic C-263 superalloy with a multilayer CVD insert. Taguchi's L-27 orthogonal array is used plan the experiments. The effects of input parameters, namely, cutting speed (V), cutting feed (F), and depth of cut (D), are studied on responses, namely, surface roughness (SR), nose wear (NW), and cutting forces (CF), under indirect, direct, and hybrid cryogenic (indirect+direct) machining environment. A scanning electron microscope (SEM) analysis is carried out to explore the postmachining outcomes on the performance measures. The multiple responses are converted into single response and ranked according to Taguchi based grey relational analysis (TGRA). Feed rate (F) is found to be the most influential parameter from the analysis of variance (ANOVA) of grey relational grade (GRG). Further, the means of GRG for each level of process parameters are used to improve the optimal process parameters. Finally, a confirmative experiment is performed on the optimum machining conditions to validate the optimization study results. It is seen that the value of GRG is improved by $9.34 \%$ when compared to the previous best result. The proposed work can be beneficial to choose ideal process conditions to enhance the performance of turning operation.
\end{abstract}

Keywords: Nimonic C-263; Hybrid cryogenics; Taguchi based Grey relational analysis (TGRA).

\section{INTRODUCTION}

Nickel alloys nowadays find a wide-ranging application in the manufacturing of critical parts for aircraft, marine, automotive, gas turbine engines, and nuclear plants owing to their capability to sustain the extreme temperature range and excellent mechanical property (Ezugwu et al., 1999; Özgün et al., 2012). Machining of these superalloys precisely and accurately has become a complex task due to high hardness value and the cost associated with the machining of these alloys. In recent years, many superalloys, namely, different grades of nickel, titanium etc., having a unique set 
of properties, have been developed for numerous engineering applications. Out of these many superalloys, Nimonic is a grade associated with nickel-based superalloy, which can function at wide range of temperatures and have a lower value of creep. Normally, they comprise $45 \%$ nickel, and $25 \%$ chromium with a smaller percentage of cobalt, aluminium, and titanium. The use of this superalloy is frequently seen in steam turbines and internal combustion (IC) engines. Various grades of alloys are based on their composition like Nimonic 75, 80A, 90, 110,105, 115, and 263 (Patel, 2006; Jadhav et al. 2019).

Nimonic C-263 is one of the important superalloys in this category that primarily contains nickel and has a specific set of properties like high hot hardness, fatigue strength, creep resistance, better thermal stability at higher temperatures, high yield strength, high oxidation resistance, and excellent ductility (Ezilarasan et al. 2011; Podder and Paul, 2012). However, several difficulties are observed while machining the Nimonic C-263 alloy as it is low conductive at higher temperature and its tendency of work hardening along with rough particle formation in its structure (Ezilarasan et al.,2014). Additionally, precipitation hardening of cobalt within the structure improves the strength of the material and makes it harder to machine. Moreover, formation of built-up-edges (BUE) during machining of Nimonic C-263 deteriorates the surface integrity and leads to rapid tool failure.

Numerous machining approaches have been implemented by various researchers for improving the efficiency of the turning process. The use of lubricants and coolants on the tool-workpiece interaction zone reduces the cutting temperature considerably. Lubricants commonly used in various industries are water based soluble oils or mineral oils. These oils are ecological threat as they have many harmful effects on workers' health. In this aspect, some researchers have studied the effect of cryogenically treated inserts (indirect technique) with different soaking duration at different temperatures to achieve improved machined surface quality (Behera et al., 2017; Chetan et al. 2016a, b; Jadhav et al. 2020; Podder and Paul, 2008; SreeramaReddy et al., 2009). Similarly, few studies report that impingement of cryogenic liquid on the machining zone (direct technique) can enhance the performance of the process (Aslantas et al., 2012; Dogra et al., 2010; Saini et al., 2012). However, reports analysing the machinability of process with the hybrid technique, i.e., combination of both indirect and direct cryogenic approaches, are extremely scarce in the literature. A combination of both beneficial techniques may further enhance the performance of turning operation. Thus, the novelty and prime motive of this study is to investigate the machinability of Nimonic C-263 workpiece under a hybrid cryogenic machining approach, i.e., machining with cryogenically treated inserts under cryogenic environment. This study explores the effect of machining parameters, namely, cutting speed (V), cutting feed (F), and depth of cut (D), which are explored on responses, namely, surface roughness (SR), nose wear (NW), and cutting forces $(\mathrm{CF})$, under the hybrid machining environment.

In addition to these studies, few researchers carried out an optimization with genetic algorithm for the turning process to get the optimum set of machining parameters (Batish et al., 2014; Tebaldo et al., 2017). Banh et al. (2018), Huu et al. (2019), and Nguyen et al. (2020a,b) also have used multiobjective optimization techniques for optimization of process parameters for EDM process, whereas Nguyen et al. (2018) used TOPSIS technique for EDM process parameters optimization. Taguchi-based grey relational analysis (TGRA) is amongst the simplest and systematic technique for dealing with multiobjective problems, and several researchers have already attempted this to their machining study conducted at various environments (Lin, 2004; Ranganathan and Senthilvelan, 2011; Sivaiah and Chakradhar, 2017; Tang et al., 2014).

Extensive study of past literature indicates that good amount of work has been reported worldwide to enhance the performance of turning process by the researchers. The literature reports abundant works on indirect cryogenic and direct cryogenics approaches to achieve improvement of machinability on various combination of work-tool pair individually (Chetan et al., 2016a, b; Gill, 2012; Podder and Paul, 2008; Pusavec et al., 2010; Sreerama Reddy et al., 2009). However, to the best of our knowledge, reports evaluating the machinability of the turning process combining the hybrid strategy of both direct and indirect are extremely scarce in the literature. Moreover, it is also observed that 
a limited number of studies have explored the machinability of Nimonic 263 workpiece in turning process. This superalloy finds abundant usage in manufacturing complex parts in gas turbine, aerospace, and automotive industries. Therefore, attempt must be made to explore the machinability of Nimonic C 263 workpiece in the hybrid cryogenic machining environment. Therefore, the proposed work attempts to evaluate the combined effect of hybrid cryogenic machining strategy, i.e., combination of direct and indirect cryogenic machining on Nimonic C263 workpiece. Taguchi based grey relational grade (TGRA) is used to convert multiple responses, namely, surface roughness, cutting forces, and tool wear, into equivalent grey relational grade (GRG). The GRG is further optimized and validated by conducting a confirmation test.

\section{EXPERIMENTAL DESIGN AND PROCEDURE}

For the experiment, cutting speed (V), cutting feed (F), and depth of cut (D) are selected as the important machining parameters, whereas surface roughness, nose wear, and cutting forces are considered as important performance measures in this study. Workpiece material selected is Nimonic C-263 bars of diameter $25 \mathrm{~mm}$ and length $125 \mathrm{~mm}$. The mechanical properties of Nimonic C-263 are as shown in the Table 1.

Table 1. Mechanical properties of Nimonic C-263 (Podder and Paul, 2012).

\begin{tabular}{|c|c|c|c|c|}
\hline Material & $\begin{array}{c}\text { Yield strength } \\
(\mathrm{MPa})\end{array}$ & $\begin{array}{c}\text { Hardness } \\
(\mathrm{HV})\end{array}$ & $\begin{array}{c}\text { Tensile strength } \\
(\mathrm{MPa})\end{array}$ & $\begin{array}{c}\text { Elastic Modulus } \\
(\mathrm{GPa})\end{array}$ \\
\hline Nimonic C-263 & 400 & 215 & 992 & 220 \\
\hline
\end{tabular}

The tool insert material used for turning was T-style tool insert with multilayer CVD coating of TiN-MT-TiCN$\mathrm{A} 12 \mathrm{O} 3$ grade $\mathrm{KCM} 25$. Each hard-turning experiment was performed twice, and the mean of the result is considered for better accuracy. Figure 1 shows the pictorial view of hybrid cryogenic experimental setup (indirect+direct), and details of the experimentation are given in Table 2 along with the level of parameters selected.

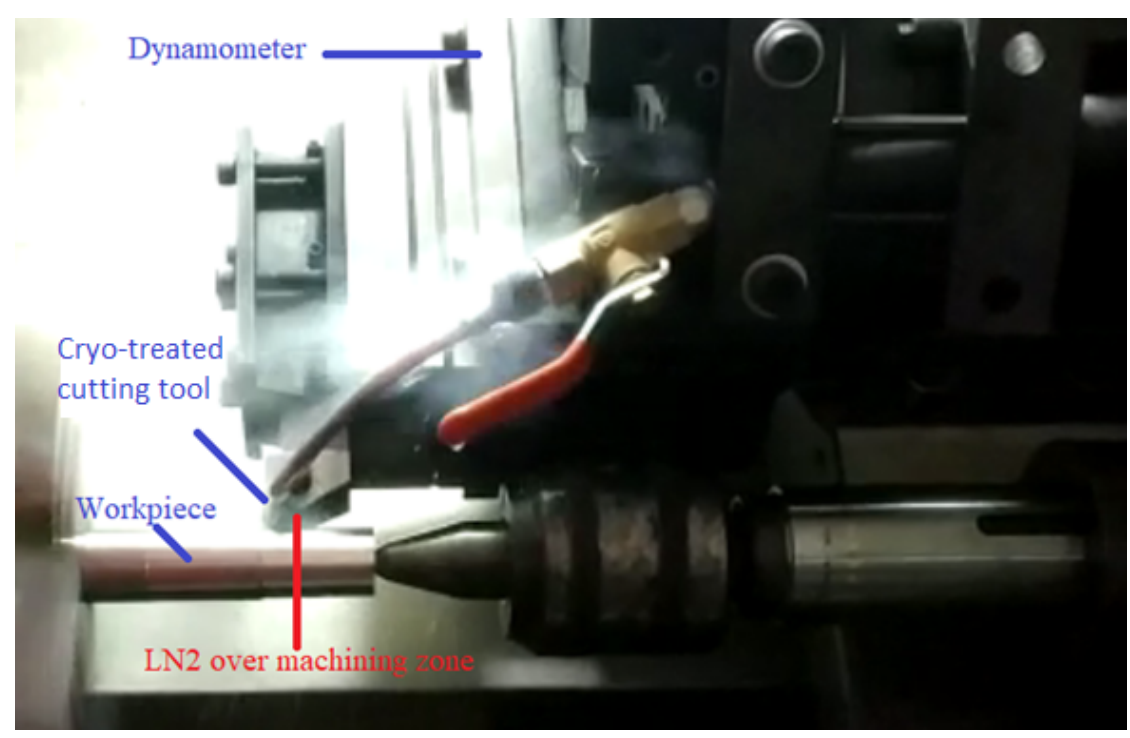

Figure 1. Hybrid cryogenic setup. 
Taguchi's robust L27 orthogonal array is used to plan the experiments with an objective of extracting maximum information from the study with minimum experimental runs. The design of experiments (DOE) and the performance analysis are done via Minitab 18 statistical software. The relation between objective value and functional value is identified and emphasized as Taguchi loss function. It is mathematically written as shown in Equation 1:

$\mathrm{L}(\mathrm{y})=\frac{\mathrm{L}(\mathrm{m})(\mathrm{y}-\mathrm{m})^{2}}{2}=\mathrm{k}(\mathrm{y}-\mathrm{m})^{2}=\mathrm{k}(\sigma)$

Here, the term y represents the value of the quality characteristic, and $\mathrm{k}$ denotes the proportionality constant; $\mathrm{L}(\mathrm{y})$ denotes the loss function; $\mathrm{m}$ denotes the target value of $\mathrm{y} ; \sigma$ represents a mean square deviation.

Table 2. Experimental details.

\begin{tabular}{|c|c|}
\hline Work piece & Nimonic C-263 alloy \\
\hline Composition (\%) & $\begin{array}{r}\text { C- 0.06, Al- 0.33, Co- 19.89, Cr- 20.41, Fe- 0.45, Mo-5.85, } \\
\text { Ti- 2.11, N- 0.006 (Balanced Ni) }\end{array}$ \\
\hline Machine & MTAB Max Turn plus CNC Machine \\
\hline Cutting Insert & Kennametal (TNMG160408MP KCM25) \\
\hline DOE & L-27 (Taguchi's approach) \\
\hline Input Parameters (3 levels) & $\begin{array}{r}\text { Cutting speed (50, 80, 110m/min), } \\
\text { Cutting Feed (0.08, } 0.1,0.12 \mathrm{~mm} / \mathrm{rev}), \\
\text { Depth of cut }(0.4,0.6,0.8 \mathrm{~mm})\end{array}$ \\
\hline Performance Measures & $\begin{array}{r}\text { Cutting forces, surface roughness and nose wear } \\
\hline\end{array}$ \\
\hline
\end{tabular}

\section{CRYOGENIC TREATMENT ON INSERTS}

Cryogenic treatment on inserts is an indirect cryogenic method, which comprises the process of treating the inserts at sub-zero condition (below $0^{\circ} \mathrm{C}$ ) to enhance their mechanical properties. For this method, various gases such as $\mathrm{CO}_{2}$, liquid nitrogen, and helium are generally used as a working medium. In this study, cryogenic treatment on the tool inserts was done to find out its effect on the response parameters along with direct cryogenics. Liquid nitrogen was used as working medium $\left(\mathrm{LN}_{2}\right)$ for this study, and the cryogenic temperature selected was $-100^{\circ} \mathrm{C}$ along with soaking duration of 12 hours. The cooling rate was throughout kept constant as $2^{\circ} \mathrm{C} / \mathrm{min}$. After this sub-zero treatment, tempering was carried out at $200^{\circ} \mathrm{C}$ on the samples to eliminate the internal residual stresses with same rate of $2^{\circ} \mathrm{C} / \mathrm{min}$ and held at that temperature for 2 hours. The inserts were then cooled down in the air slowly. The optimal specifications for cryogenic treatment were selected by referring previous literatures (Chetan et al., 2016a; Gill, 2012; Pusavec et al., 2010). Figure 2 shows the timeline of the various heat treatment processes. 


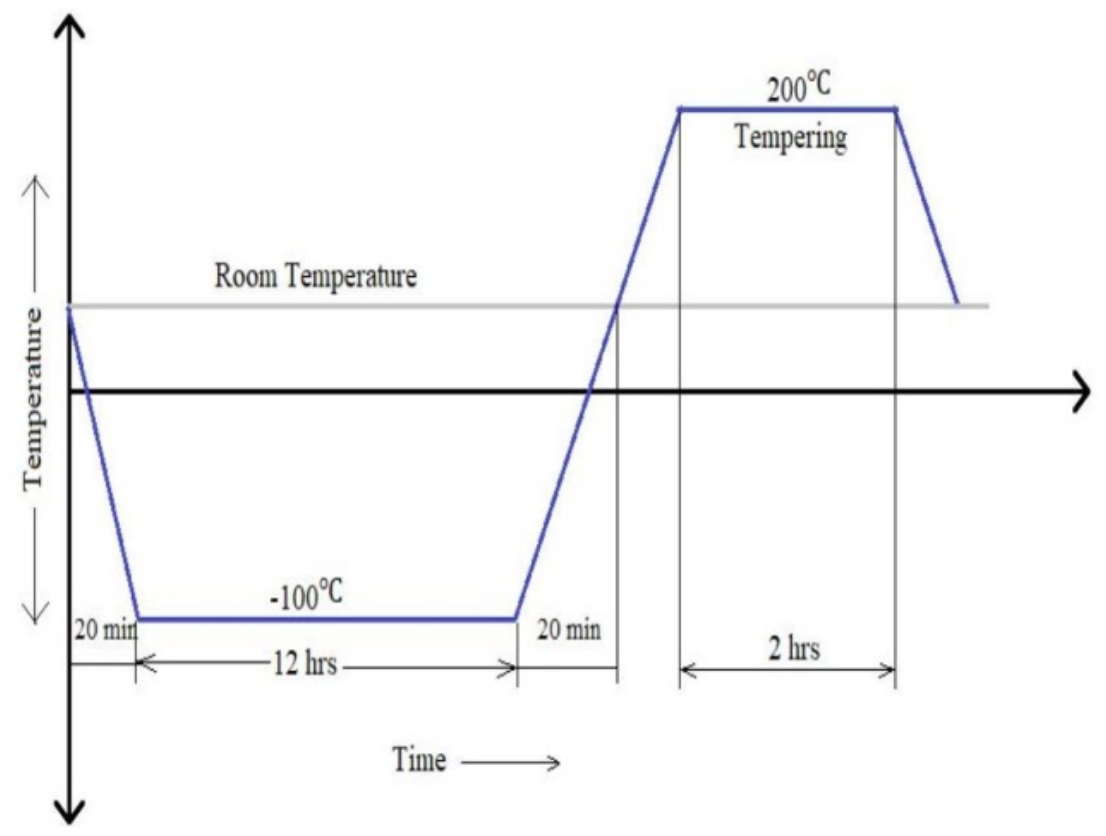

Figure 2. Heat treatment timeline followed for tool insert.

The microstructural examination is carried out by using scanning electronic microscope (Leica/Cambridge LeoStereoscan, S-440) as per ASTM (B-657/05) regulations for cryogenically untreated and treated inserts. This confirmed the development of eta particles in the matrix. Figure 3(a) and figure 3(b) show the microstructure of untreated and treated inserts, respectively. It is clearly seen that the cryogenic treatment has resulted in the development of finer distributed eta particles compared to the coarser distributed grains in untreated inserts.
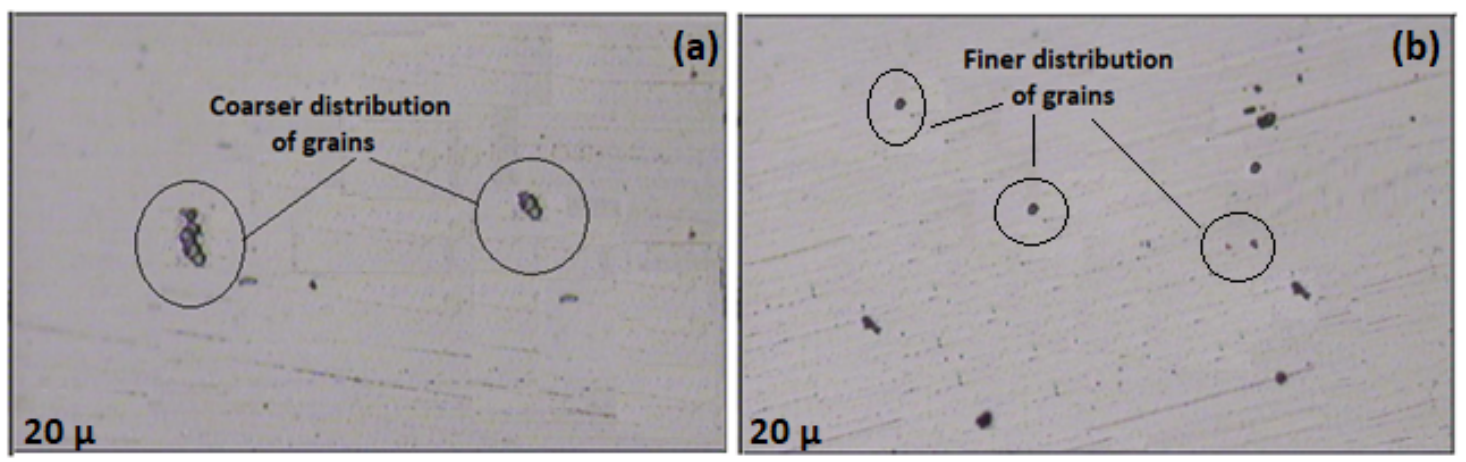

Figure 3. Microstructural study: (a) coarser grains in untreated inserts; (b) finer distribution in cryo-treated inserts.

The cryogenic treatment also improves the microhardness values of carbide inserts. This has also been supported by few previous studies (Chetan et al., 2017; Thakur et al., 2008). This is primarily due to the fact that, with cryogenic treatment, there is formation of eta precipitates. The X ray diffraction (XRD) analysis (PW-3710, diffractometer with a $\mathrm{Cr} \mathrm{K}, \lambda=2.2870 \mathrm{~A}^{\circ}$ target) of the untreated and treated inserts is carried out to validate this eta formation, and the results are shown in figure 4 . The presence of tiny sharp peaks after the cryogenic treatment observed in the XRD 
profile implies the formation of complex compound carbide phases. Moreover, grain refinement at lower temperature is another reason for this improvement in the hardness values of cryo-treated insert.

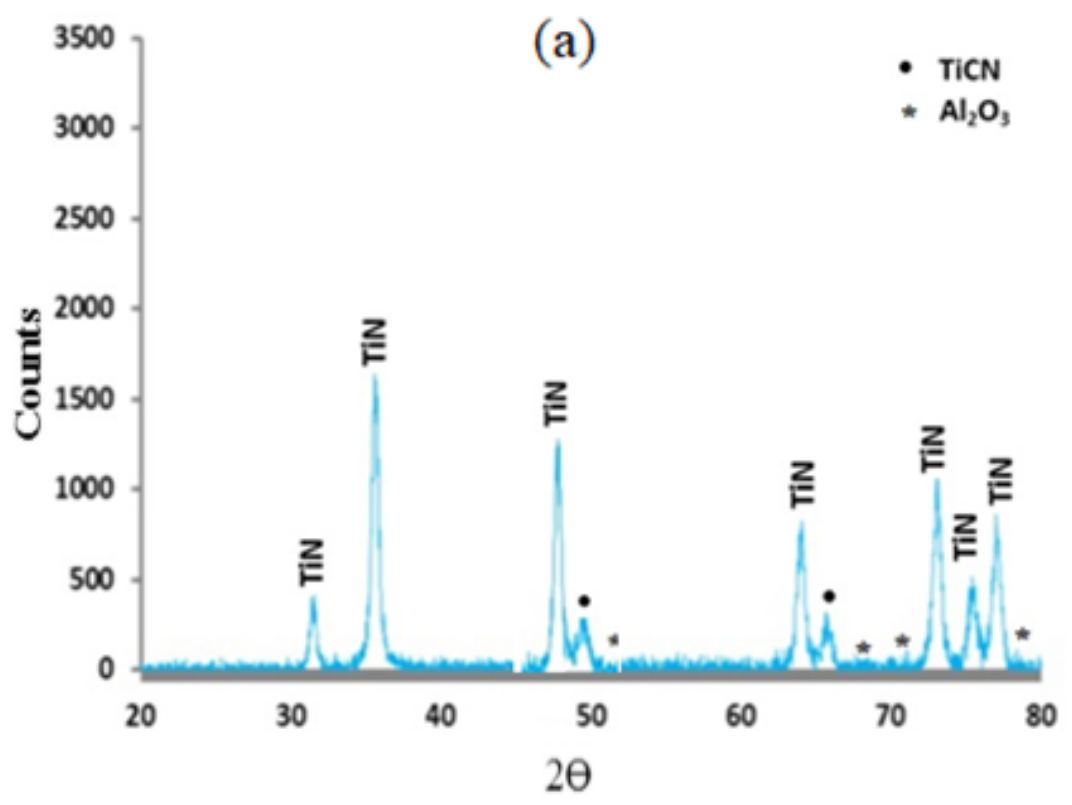

(b)

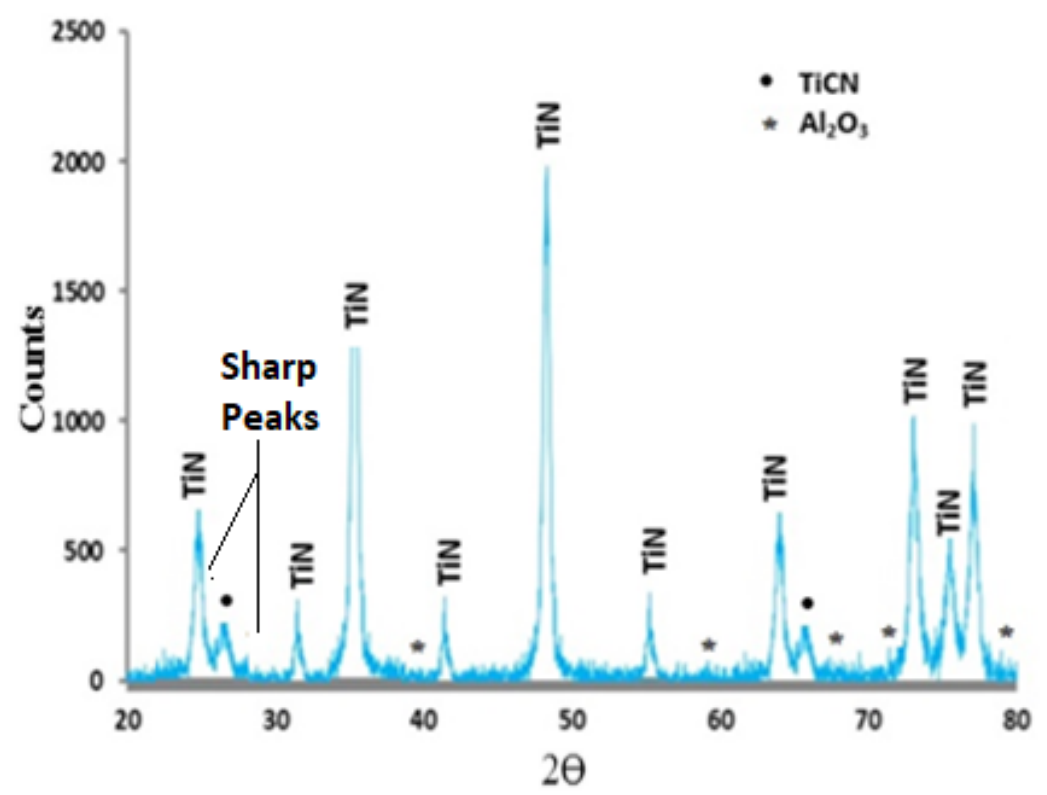

Figure 4. XRD pattern for the (a) untreated tool and (b) treated tool insert. 
To validate this again, a full width at half maxima (FWHM) received from XRD pattern is studied. FWHM corresponds to the enlargement of peaks, which further are associated with the grain refinement. Figure 5 reveals the variation of FWHM for untreated and treated inserts corresponding to the diffraction angle (20). FWHM value can be seen larger in case of cryo-treated inserts as compared to the untreated inserts. Larger FWHM value in carbide insert implies the additional refinement of grains that resulted in an increased value of hardness. Further, to determine the effect of cryogenic treatment on grain refinement, the Scherrer formula was used to estimate the grain size from $\mathrm{XRD}$ curve as per Equation 2:

$\mathrm{D}=\frac{\mathrm{K} \lambda}{\beta \cos \theta}$

where $\mathrm{D}$ is the grain size $(\mathrm{nm}),(2 \theta)$ is the diffraction caused by grain refinement peak broadening (radian), $\lambda$ is the X-ray wavelength $(\mathrm{nm}), \theta$ is the diffraction angle (degree), and $\mathrm{K}$ is a constant $(\mathrm{K}=0.89)$. The average grain size of the insert before cryogenic treatment was $0.923 \mu \mathrm{m}$, and the refinement was observed after the treatment up to an average size of $0.827 \mu \mathrm{m}$. This is also supported by previous researches, in which they also claimed that the refinement of grains occurred through the cryogenic treatment increases the hardness and wear resistance of tungsten carbide inserts (Antonialli et al., 2016; Gill, 2012; Ranganathan \& Senthilvelan, 2011).

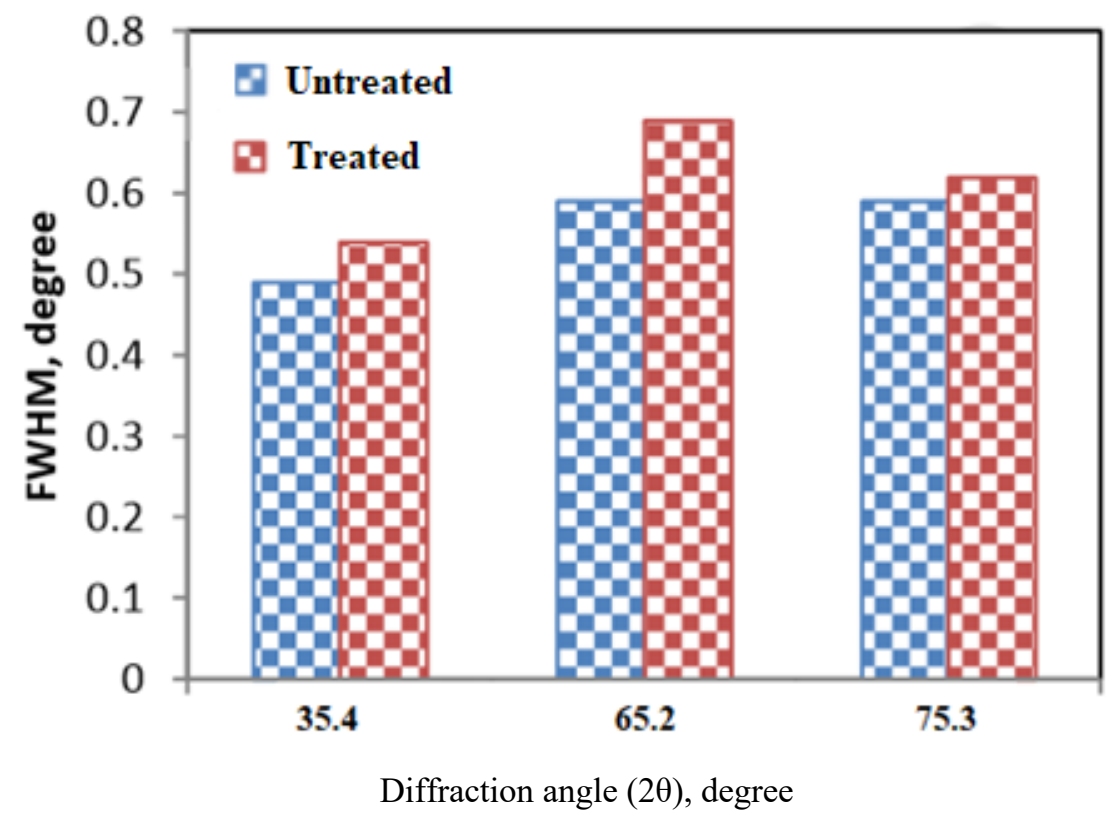

Figure 5. FWHM Vs. diffraction angle for untreated and treated inserts.

\section{CRYOGENIC MACHINING ENVIRONMENT}

This is also known as a direct method of cryogenics, where the jet of $\mathrm{CO}_{2}$, and $\mathrm{LN}_{2}$ is projected directly over the cutting zone. Many researchers have achieved increase in tool life with the help of cryogenic cooling. This method removes heat from cutting zone, and at the same time, it also reduces the coefficient of friction by providing cushioning effect between chip-tool interface. Liquid nitrogen at $-196^{\circ} \mathrm{C}$ has commonly been used as a coolant in the cryogenic machining. Liquid nitrogen is an inert gas, and also, it is not dangerous to the workers on the shop floor. 
Also, it minimizes the diffusion wear and adhesion performance of cutting tool and hence increases the tool life. Figure 6 is the block diagram of the direct cryogenic setup prepared for the same.

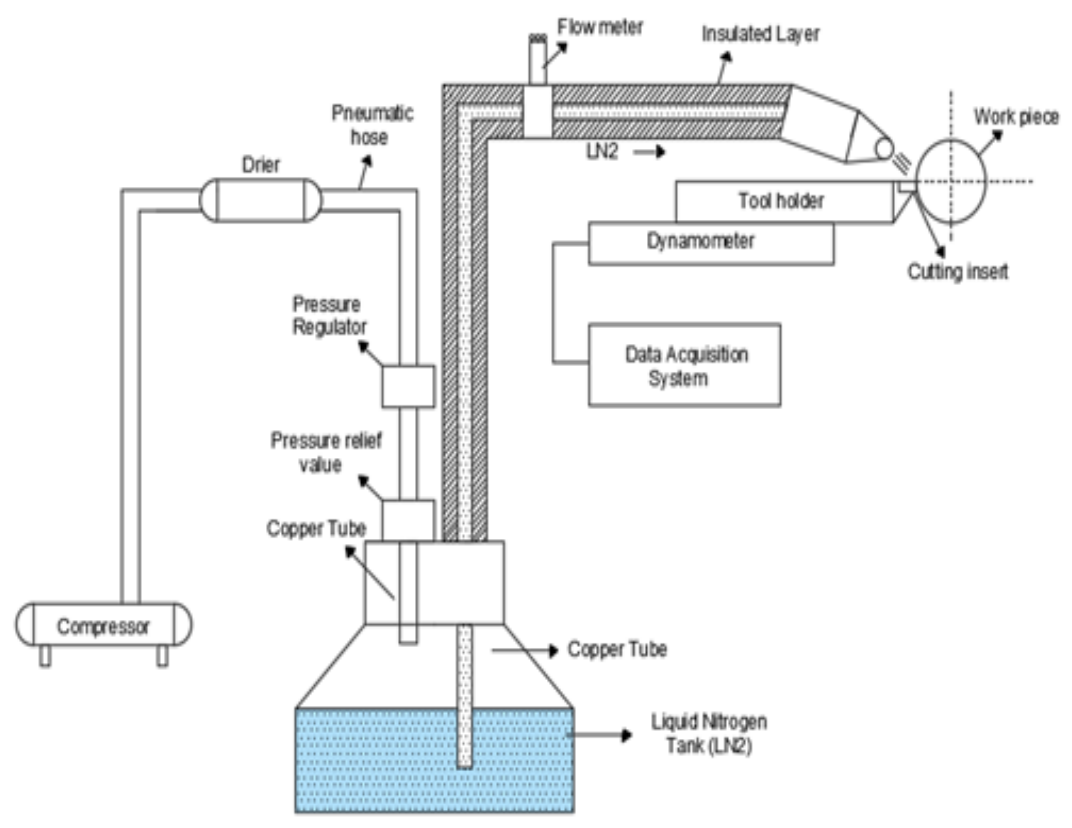

Figure 6. Block diagram of direct cryogenics setup.

\section{MEASUREMENT OF RESPONSES}

\section{Surface Roughness Measurement}

The surface roughness (SR) testing was carried out with the help of Taylor Hobson Talysurf surface roughness tester (Mitutoyo made). The workpiece was rotated randomly, and 4 readings were taken at $90^{\circ}$ angle each. The average of these readings ( $\mathrm{Ra}$ in microns) was taken as the final value of surface roughness.

\section{Tool Wear Measurement}

The nose wear (NW) was carried out using Toolmakers' microscope (Mitutoyo made). The tool insert is placed on the glass below the lens of 10X magnification power. All the readings were taken twice, and the average is taken for better accuracy. The readings are expressed in millimetre.

\section{Cutting Force Measurement}

The cutting force (CF) was measured using lathe tool dynamometer 5233A (Kistler made). The data procurement system comprises DynoWare software and force values are expressed in newton $(\mathrm{N})$. Figure 7 shows the data acquisition system for cutting forces from DynoWare software in which Fx, Fy, and Fz show cutting force, thrust force, and feed force, respectively. Out of these forces, the cutting force value (Fx) is considered for the analysis. 


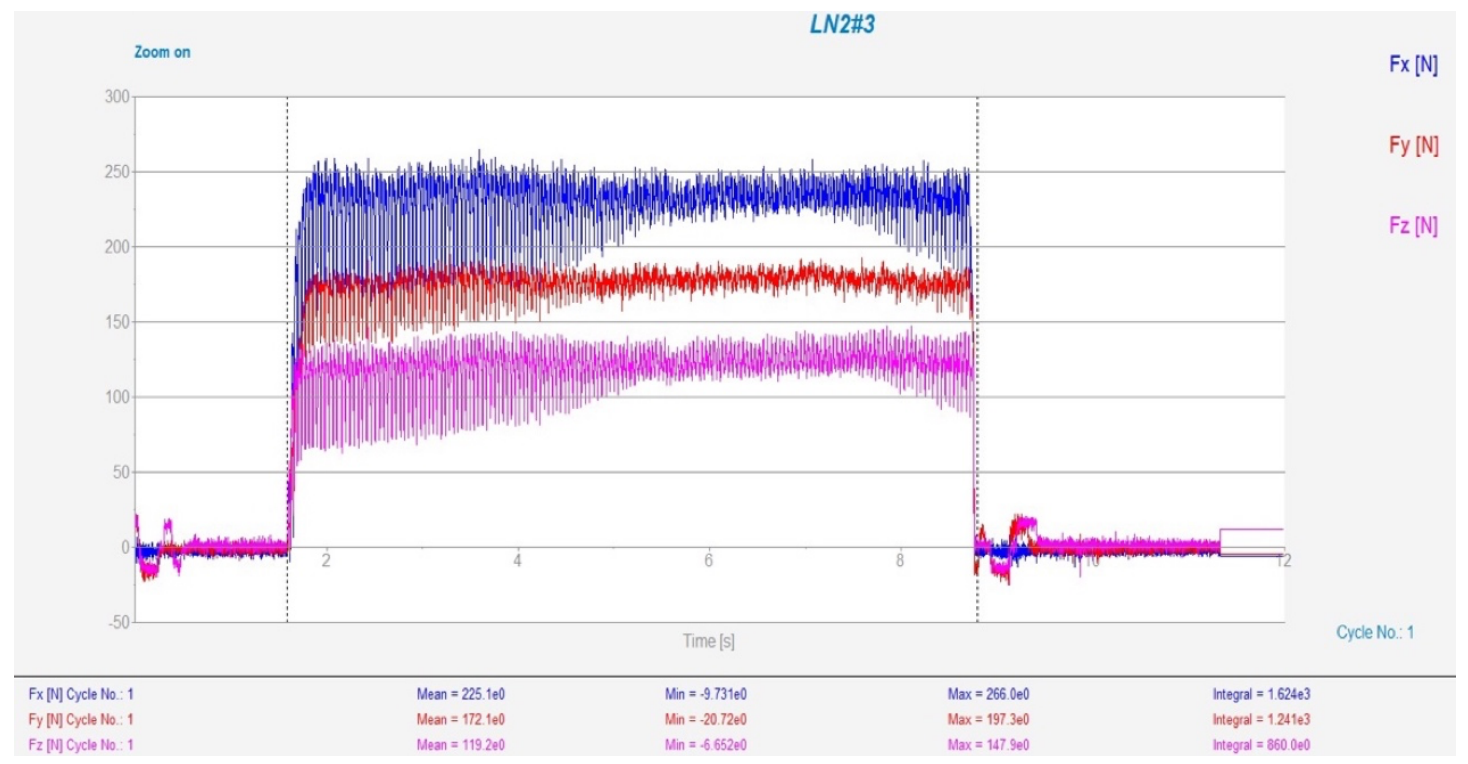

Figure 7. Data acquisition system of DynoWare software for cutting forces.

\section{RESULTS AND DISCUSSION}

Table 3 shows the Taguchi's L-27 orthogonal array of twenty-seven experimental runs along with the comparative values of responses, namely, surface roughness (SR), nose wear (NW), and cutting forces (CF), for direct, indirect, and hybrid (indirect+direct) cryogenics, respectively. Figure 8 shows the comparison of responses, namely, surface roughness, nose wear, and cutting forces, for indirect, direct, and hybrid cryogenics. From table 3 and figures 8(a), (b), and (c), it is clearly observed that the hybrid approach delivers the best responses. It is also seen that the cutting forces generated during direct cryogenics are comparatively lesser with respect to the indirect cryogenics, whereas nose wear is significantly lesser during indirect cryogenics when compared to the direct cryogenics. This is due to the fact that treated tool shows improved hardness and wear resistance compared to the untreated tools, which is also reported by earlier researchers (Chetan et al., 2017; Thakur et al., 2008). This clearly confirms that the hybrid cryogenics approach has the upper hand over direct and indirect approaches in isolation. Hence, the hybrid approach is considered for the further optimization process. Table 4 comprises hybrid approach responses, Grey relational coefficients (GRC), Grey relational grade (GRG), and rank after Taguchi based grey relational analysis operations. 


\section{(a) Comparision of surface roughness}

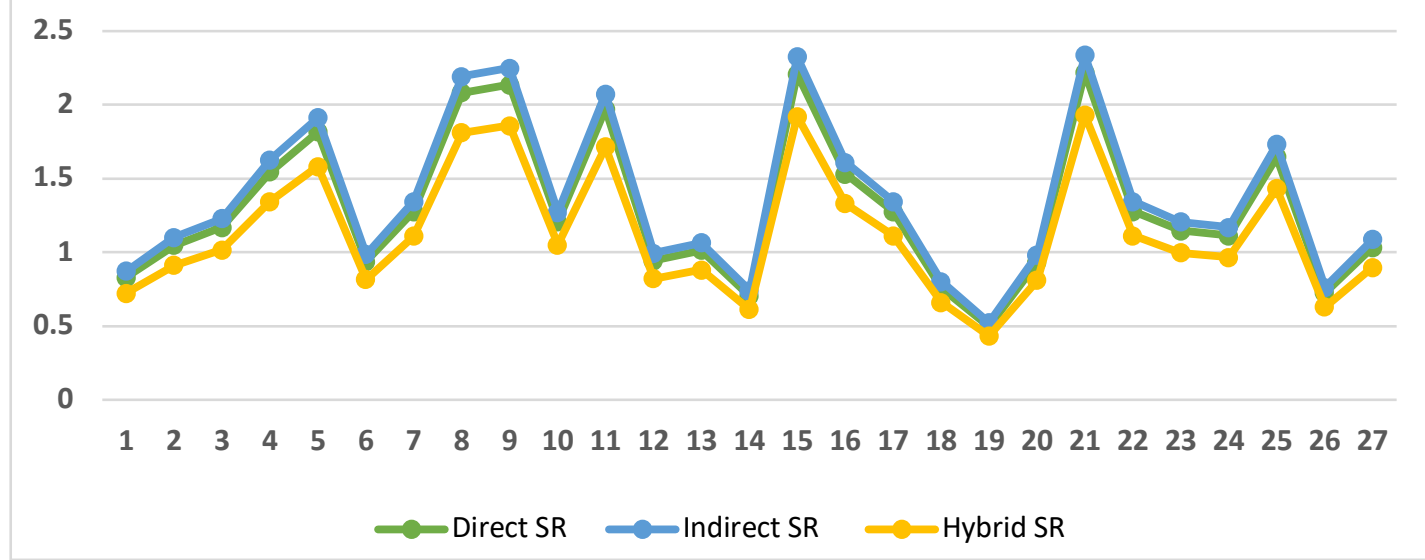

(b) Comparision of nose wear

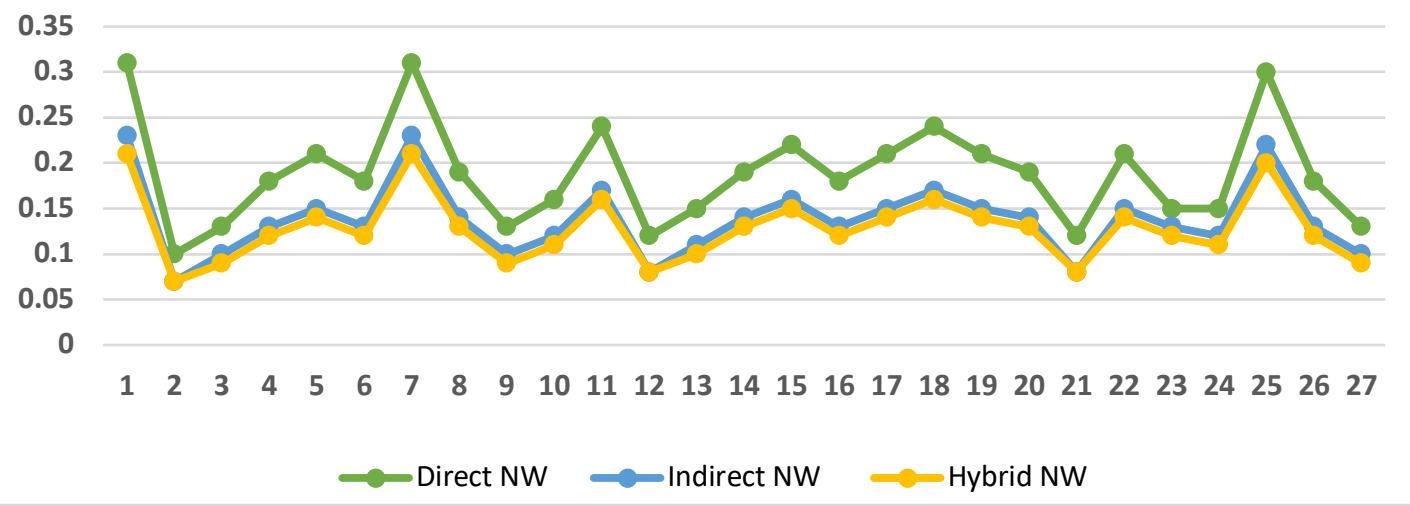

(c) Comparision of cutting forces

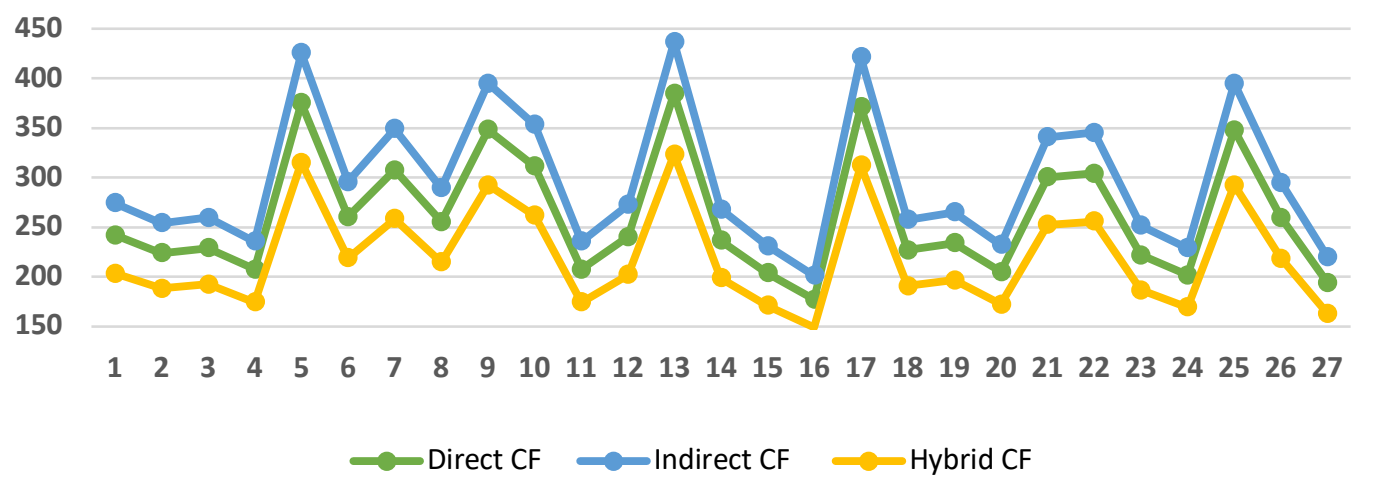

Figure 8. Comparison of responses for direct, indirect, and hybrid cryogenics:

(a) surface roughness; (b) nose wear; (c) cutting force. 


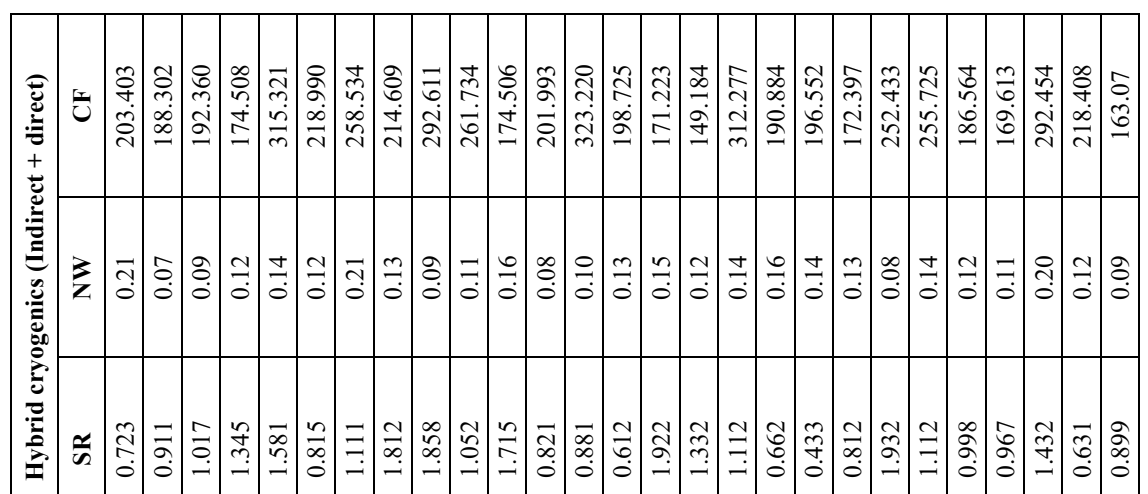

守定

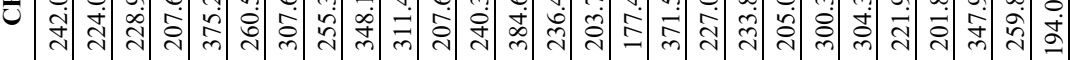

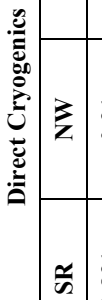

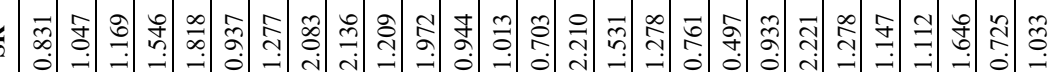

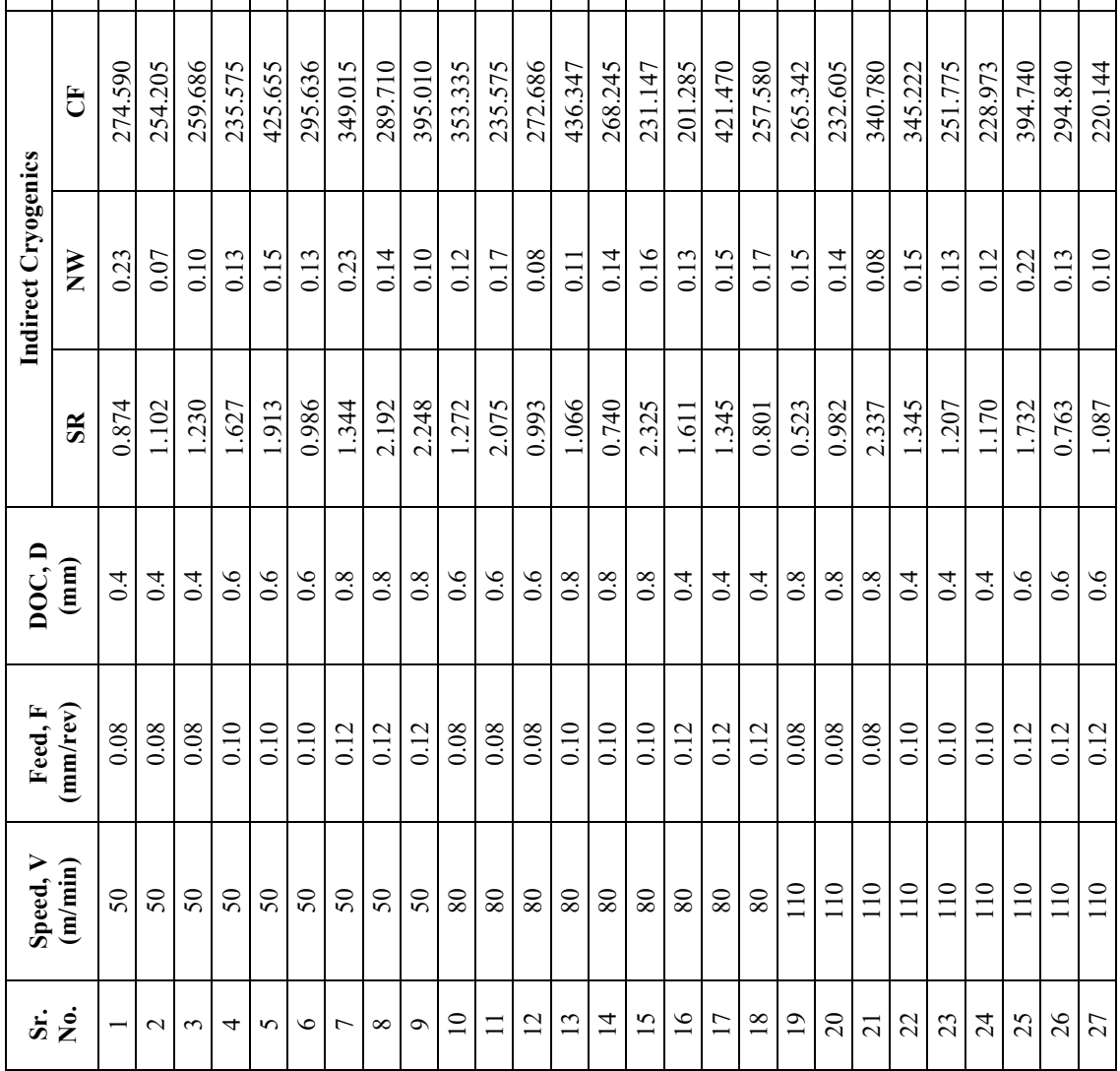




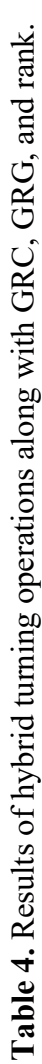

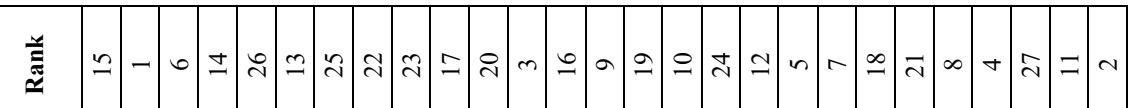

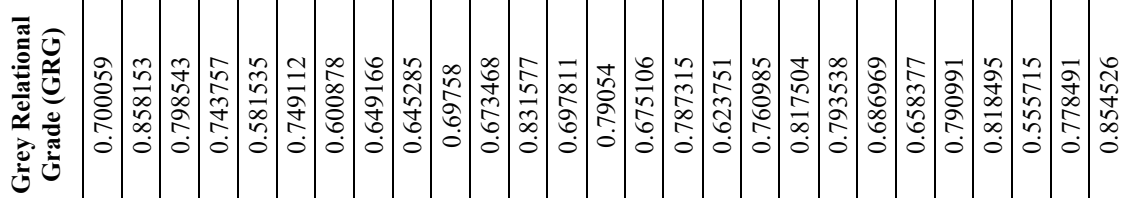

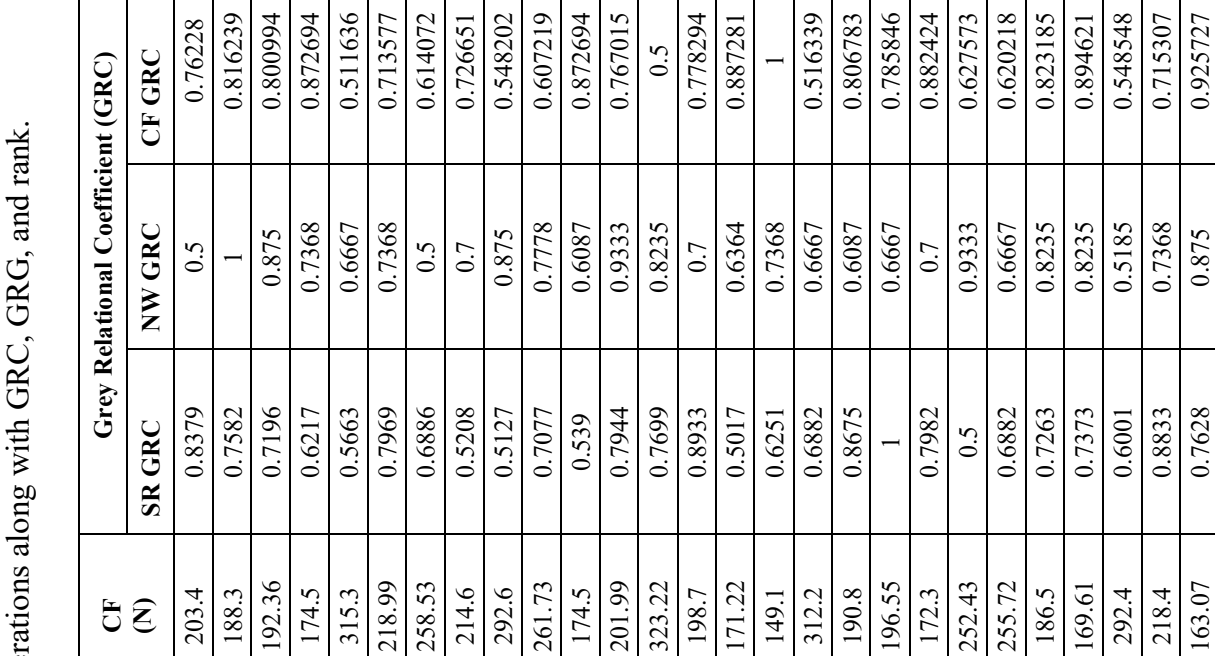
考者

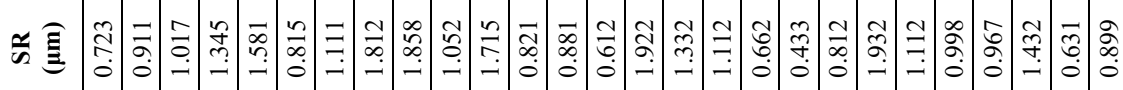

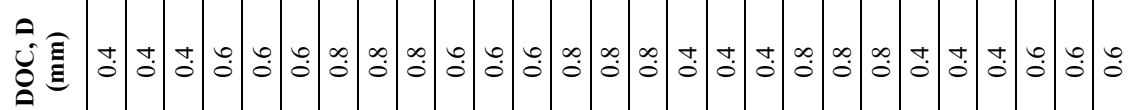

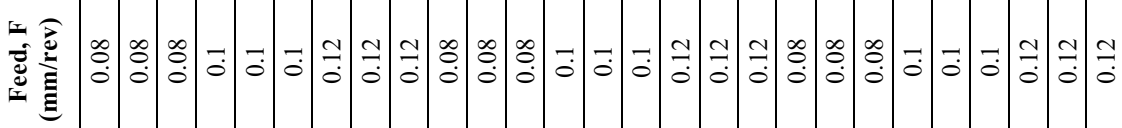

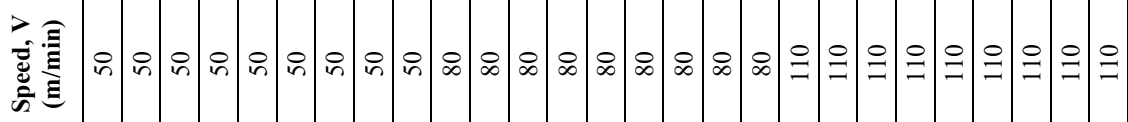

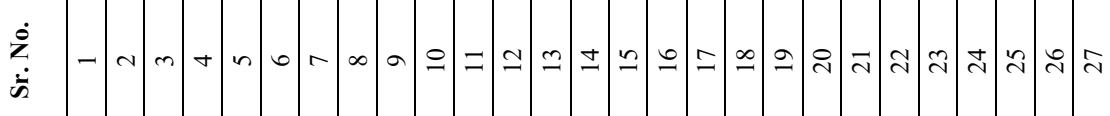




\section{Analysis of Surface Roughness}

Surface roughness is one of the crucial responses in hard turning process as it influences the tool wear and tribological properties of machined surface. The effect of different input variables, namely, spindle speed, feed, and depth of cut, is studied individually on responses like surface roughness, nose wear, and cutting forces in this section. Figure 9 shows the main effect plot values for surface roughness measured at different levels of cutting speed (50, 80 , and $110 \mathrm{~m} / \mathrm{min})$, depth of cut $(0.4,0.6$, and $0.8 \mathrm{~mm})$, and feed rate $(0.08,0.1$, and $0.12 \mathrm{~mm} / \mathrm{rev})$.

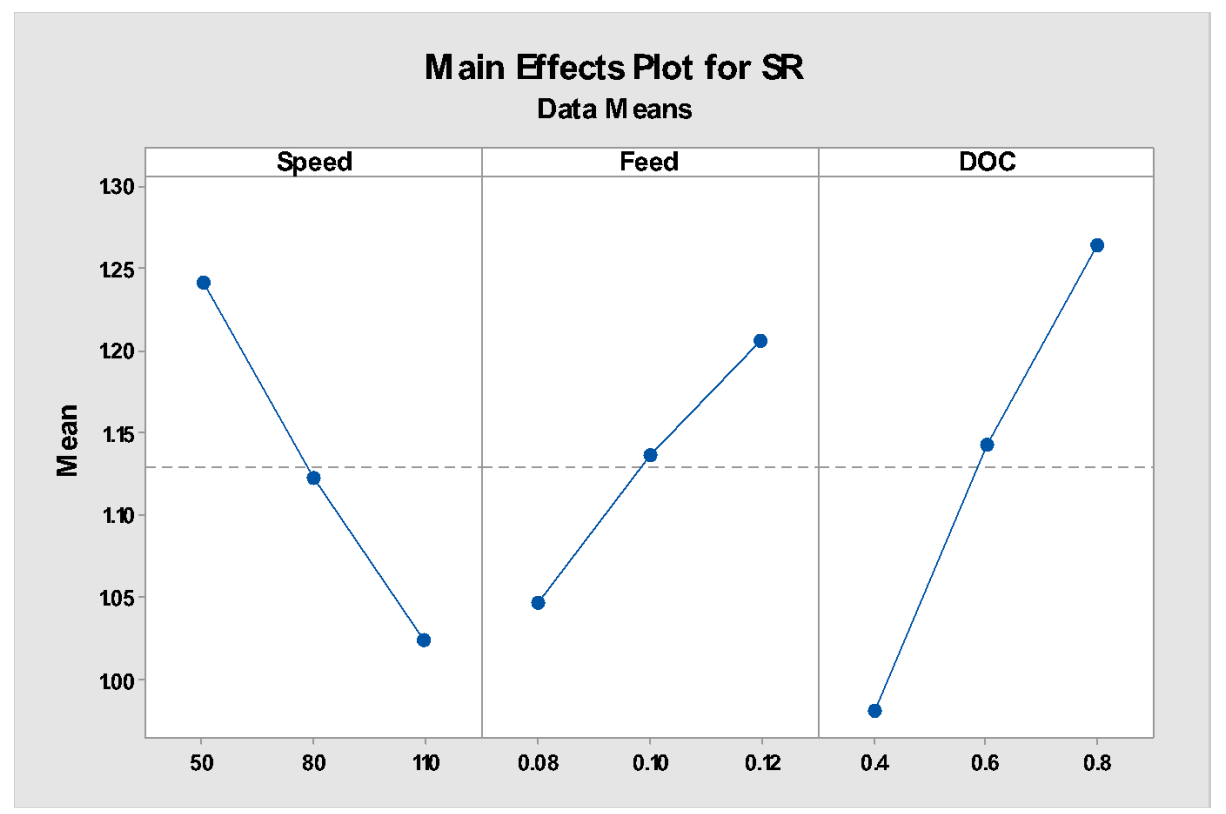

Figure 9. Main effect plot for surface roughness.

From the main effect plot, it is observed that the value of surface roughness has been reduced with increasing speed. Figure also shows the incremental trend in the values of surface roughness with an increasing cutting feed value. This is due to the fact that the cutting load increases over the tool with increasing feed rate that leads to excess frequency of vibrations of tool resulting into poor surface finish. The best surface finish is obtained at the lowest cutting feed and highest spindle speed combination. Figure also shows that if the depth of cut is increased, the surface finish obtained will be very poor. This is due to the excessive rubbing action and temperature rise with an increasing depth of cut that causes an increase in the surface roughness value.

\section{Analysis of Tool Wear}

Tool wear is also the most crucial response as it affects the dimensional exactness and surface integrity of the machined component. It is also an important aspect that decides the tool life, which is ultimately associated with the cost of machining. In machining, the nose wear is responsible for the cutting-edge retreat and has a greater influence on the dimensional accuracy of a workpiece. Figure 10 shows the main effect plots for the nose wear obtained below the ISO 3658-1993 standards. 


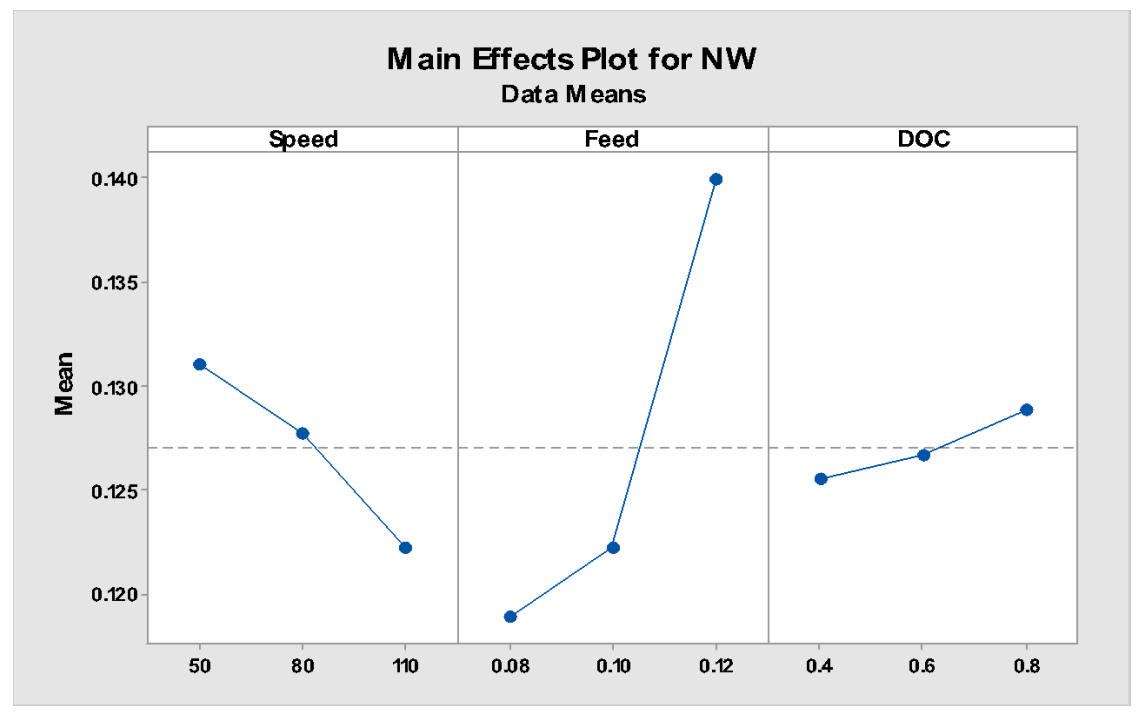

Figure 10. Main effect plot for nose wear.

For the spindle speed of $110 \mathrm{~m} / \mathrm{min}$, the value of the tool wear is least till $0.122 \mu \mathrm{m}$. Further, it is also evident from the graphs that, at $110 \mathrm{~m} / \mathrm{min}$ of spindle speed, the tool wear is reduced approximately by $25 \%$ as compared to the lower speed of $50 \mathrm{~m} / \mathrm{min}$.

\section{Analysis of Cutting Forces}

Cutting force generation influences the stability of a machining system. It may deform the workpiece with nonuniform chip formation, and dimensional accuracy may be lost. Figure 11 shows the main effect plots for cutting forces, which show that, at the higher cutting feed and lower spindle speed, the cutting force generation is on the peak.

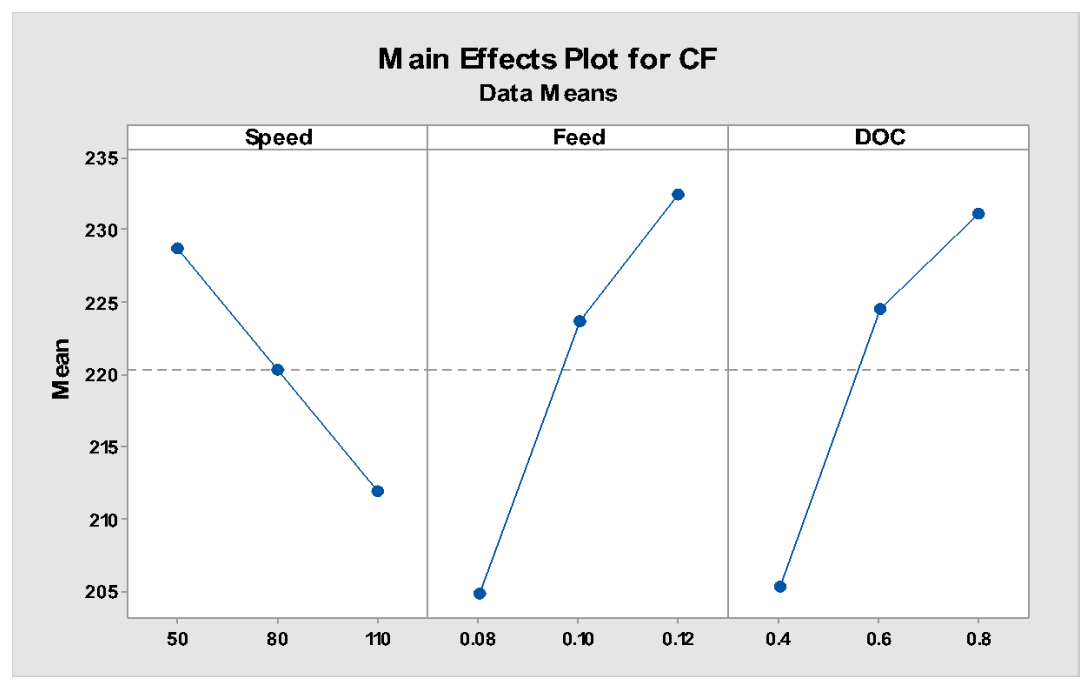

Figure 11. Main effect plot for cutting forces. 
The extreme high value of cutting forces measured was approximately $223 \mathrm{~N}$ for the spindle speed of $50 \mathrm{~m} / \mathrm{min}$, $0.12 \mathrm{~mm} / \mathrm{rev}$ for the feed, and $0.8 \mathrm{~mm}$ for the depth of cut, whereas the lowest cutting force was observed at the maximum speed of $110 \mathrm{~m} / \mathrm{min}$, minimum feed rate of $0.08 \mathrm{~mm} / \mathrm{rev}$, and lowest depth of cut of $0.4 \mathrm{~mm}$. This is because at lower cutting speeds, residual stresses formed in the workpiece are of tensile in nature, and if the depth of these stresses is increased, then the cutting force generated at the zone is higher. A similar observation has been reported by previous researchers (Ozel et al., 2005).

\section{GREY RELATIONAL ANALYSIS}

Taguchi-based grey relational analysis (TGRA) is familiar for treating problems having interfunctional relationship among multiple input parameters and response variables. Multiple input parameters considered in this study are the cutting parameters, namely, cutting speed (V), feed rate (F), and depth of cut (D). Table 3 shows the level of input parameters and the associated readings considered for multioptimization. Twenty-seven different sets of experiments are carried out in this study, which are further optimized using Taguchi-based grey relational analysis. The responses considered during this study are, namely, surface roughness, nose wear, and cutting forces. These machining performances were transformed to the single common dataset by estimating grey relational grade, i.e., GRG (Tang et al., 2014).

\section{a) Data Set Normalization}

As the motive is to estimate an optimum range of input variables yielding minimal values of surface roughness, nose wear, and cutting forces, lower-is-better model is implemented as per Equation (2). The normalized value $\mathrm{Xi} *(\mathrm{j})$ of $\mathrm{Xi}(\mathrm{j})$ is obtained by equation (3):

$X i *(j)=\frac{\max j . X i(j)-X i(j)}{\max j \cdot X i(j)-\min j \cdot X i(j)}$

where max $\mathrm{j} . \mathrm{Xi}(\mathrm{j})$ is the highest $\mathrm{j}$ value, and $\min \mathrm{j} . \mathrm{Xi}(\mathrm{j})$ is the lowest $\mathrm{j}$ value.

\section{b) Estimating Grey Relational Coefficient (GRC)}

Grey relational coefficient $f 0 i(j)$ is estimated by equation (4):

$f 0 i(j)=\frac{\Delta \min +£ \Delta \max }{\Delta 0 \mathrm{i}(\mathrm{j})+£ \Delta \max }$

where $\Delta 0 \mathrm{i}(\mathrm{j})=\mathrm{X} 0 *(\mathrm{j})-\mathrm{Xi}(\mathrm{j})$ is the trend showing deviation for $\Delta 0 \mathrm{i}(\mathrm{j})$,

$\Delta \max =\operatorname{maximaxj} \Delta 0 \mathrm{i}(\mathrm{j}), \Delta \min =\min$ i.min $\mathrm{j} \Delta 0 \mathrm{i}(\mathrm{j})$, and $f$ is distinguishing factor, $f \varepsilon[0,1]$.

\section{c) Estimation of Grey Relational grade (GRG)}

After GRC, grey relational grade can be estimated by equation (5):

$f 0 i=\sum_{\mathrm{j}=1}^{n} \mathrm{Wi}(\mathrm{j}) \times \gamma 0 \mathrm{i}(\mathrm{j})$ 


\section{d) Assigning the Rank to a Data}

The highest value of GRG is assumed to be the most influential combination and is assigned with rank accordingly. GRG was estimated for all set of data values, and it is used to identify the most significant levels of input parameters at which improved results are obtained. Table 3 shows GRC, GRG, and rank for the experimental values, whereas Table 4 shows mean of GRG values for each level. The larger GRG value implies the degree of closeness of experimental response to the ideal value. In table 5, it is observed that second experimental combination shows the largest amongst all the 27 experiments. The GRG value is further analysed by using ANOVA to analyse the influence of individual parameter on the value of grey relational grade.

Table 5. Response table for GRG.

\begin{tabular}{|c|c|c|c|c|c|c|}
\hline \multirow{2}{*}{ Symbol } & \multirow{2}{*}{$\begin{array}{c}\text { Process } \\
\text { parameters }\end{array}$} & \multicolumn{5}{|c|}{ Grey relational grade } \\
\cline { 3 - 7 } & Level 1 & Level 2 & Level 3 & Delta & Rank \\
\hline $\mathrm{V}$ & $\begin{array}{c}\text { Cutting speed } \\
(\mathrm{m} / \mathrm{min})\end{array}$ & 0.7029 & 0.7264 & 0.7505 & 0.0476 & 3 \\
\hline $\mathrm{F}$ & $\begin{array}{c}\text { Cutting feed } \\
(\mathrm{mm} / \mathrm{rev})\end{array}$ & 0.7619 & 0.7228 & 0.6951 & 0.0668 & 1 \\
\hline $\mathrm{D}$ & $\begin{array}{c}\text { Depth of cut } \\
(\mathrm{mm})\end{array}$ & 0.7551 & 0.7184 & 0.7063 & 0.0488 & 2 \\
\hline
\end{tabular}

\section{ANALYSIS OF VARIANCE (ANOVA)}

The motive of ANOVA is to find out the most significant machining parameters that influence machining process. It provides the data such as degrees of freedom, sum of squares, mean squares, F-value, P-value, and \% contribution of parameters. Table 6 illustrates the ANOVA results, which clearly show that a cutting feed is the most significant attribute in cryogenic hard turning of Nimonic C-263 superalloy that contributes $48.33 \%$. Past research also found the same trend of results (Goel et al., 2015). It can also be seen that the spindle speed has $14.90 \%$ contribution, whereas the depth of cut has $36.77 \%$ contribution on the performance of hard turning.

Table 6. ANOVA for GRG.

\begin{tabular}{|c|c|c|c|c|}
\hline Source & DF & Adj SS & Adj MS & \% contribution \\
\hline Speed & 2 & 0.013322 & 0.006661 & 14.90 \\
\hline Feed & 2 & 0.043214 & 0.021607 & 48.33 \\
\hline Depth of cut & 2 & 0.032876 & 0.016438 & 36.77 \\
\hline Total & 6 & 0.089412 & & \\
\hline
\end{tabular}




\section{CONFIRMATION EXPERIMENTS}

The trial experiments were conducted as a confirmation test considering optimum combination of machining parameters to validate the TGRA. The predicted grey relational grade $\Gamma$ projected is estimated using equation (6):

$\Gamma_{\text {projected }}=\Gamma^{m}+\sum_{i=1}^{\mathrm{j}}\left(\Gamma^{0} 0-\Gamma^{\prime} \mathrm{m}\right)$

where $\Gamma$ m implies the mean of total GRG, ${ }^{0}$ implies average of the optimal levels GRG, and $\mathrm{j}$ is total no. of the input parameters.

The predicted GRG for optimum parameters is computed from equation (5) and is tabulated in the Table 6. The experimental trial was carried out as confirmation test, and their results were compared with the values of first ranked set, i.e., $2^{\text {nd }}$ orthogonal array. Table 7 confirms that there is reduction in cutting force from $188.3 \mathrm{~N}$ to $161.14 \mathrm{~N}$, surface roughness reduced from $0.911 \mu \mathrm{m}$ to $0.837 \mu \mathrm{m}$, tool nose wear reduced from $0.07 \mathrm{~mm}$ to 0.06 $\mathrm{mm}$, and GRG improved by $9.34 \%$. These results are also supported by previous studies (Ranganathan and Senthilvelan, 2011; Senthilkumar et al., 2014; Tang and Du., 2014). Hence, the above results show that there is a considerable improvement observed in the machining performance during extremely difficult to machine Nimonic C-263 material with the Taguchi-based grey relational analysis.

Table 7. Results of turning operations in confirmation test.

\begin{tabular}{|c|c|c|c|}
\hline & \multirow{2}{*}{$\begin{array}{c}\text { Orthogonal } \\
\text { trial No 2 }\end{array}$} & \multicolumn{2}{|c|}{ Optimal machining parameters using TGRA } \\
\cline { 3 - 4 } & $\mathrm{V}_{1} \mathrm{~F}_{1} \mathrm{D}_{1}$ & $\mathrm{~V}_{3} \mathrm{~F}_{1} \mathrm{D}_{1}$ & Experimental \\
\hline Level & 0.911 & & $\mathrm{~V}_{3} \mathrm{~F}_{1} \mathrm{D}_{1}$ \\
\hline Surface Roughness $(\mu \mathrm{m})$ & 0.07 & & 0.837 \\
\hline Nose wear $(\mathrm{mm})$ & 188.3 & & 0.06 \\
\hline Cutting forces $(\mathrm{N})$ & 0.8581 & 0.8992 & 161.14 \\
\hline Grey relational grade $(\mathrm{GRG})$ & & & 0.9383 \\
\hline
\end{tabular}

The improvement in $\mathrm{GRG}=0.0802$

The percentage improvement in GRG $=9.34 \%$

After selection of the optimum machining parameters, a $14.42 \%$ reduction was observed in the cutting forces in comparison to the machining parameters of $2^{\text {nd }}$ orthogonal array. This is due to the fact that the excessive temperature generated at higher spindle speeds caused thermal softening of the workpiece; moreover, the $\mathrm{LN}_{2}$ overmachining zone exhibited the cushioning effect. This resulted in reduced machining zone friction, which ultimately decreased the tooltip shearing area. At the selected optimum machining parameters, surface finish was observed to be improved by $8 \%$ compared to the $2^{\text {nd }}$ orthogonal array. Figure 12 shows the scanning electron microscope (SEM) morphologies of machined surface in which the $2^{\text {nd }}$ orthogonal array image is shown in figure 
12(a), whereas the image obtained with optimal process parameters is illustrated in figure 12(b). This clearly shows the microcavities on the surface for $2^{\text {nd }}$ orthogonal array. On the other hand, optimal machining parameters show comparatively better surface morphology. This is primarily due to the fact that the region in the vicinity of chip-tool interface is thermally softened at higher temperatures, which leads to the minimization of surface flaws and discontinuities at the machining zone. This is also supported by the previous researchers (Pawade et al., 2007; Sivaiah \& Chakradhar, 2017).
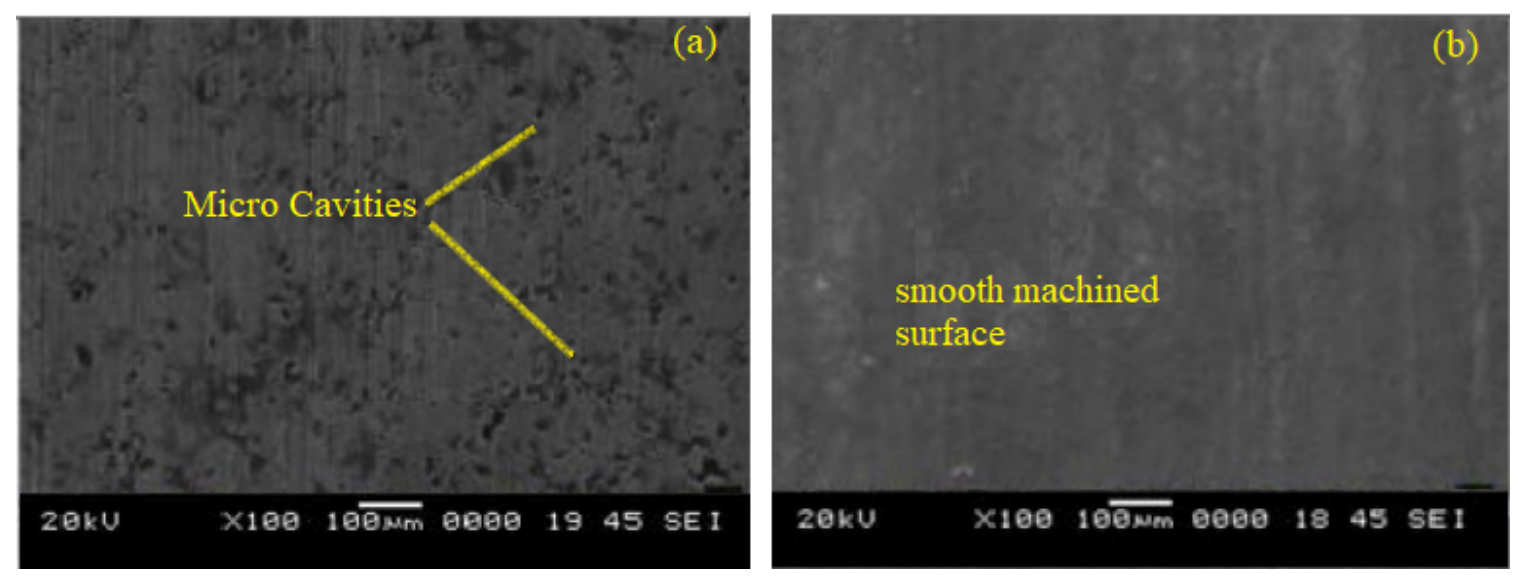

Figure 12. SEM morphology of machined surface: (a) $2^{\text {nd }}$ orthogonal array $\left(\mathrm{V}_{1} \mathrm{~F}_{1} \mathrm{D}_{1}\right)$; (b) optimum machining condition based on TGRA $\left(\mathrm{V}_{3} \mathrm{~F}_{1} \mathrm{D}_{1}\right)$.

Figures 13 (a) and 13 (b) show the SEM images of the tool morphology after machining with 2nd orthogonal array and optimized machining parameters, respectively. Rapid tool wear is observed at the morphology obtained with 2 nd orthogonal array machining parameters. The reason of this tool wear is primarily due to the abrasion and weakening of the section. On the other hand, less damage is observed in the morphology obtained with optimal machining parameters.
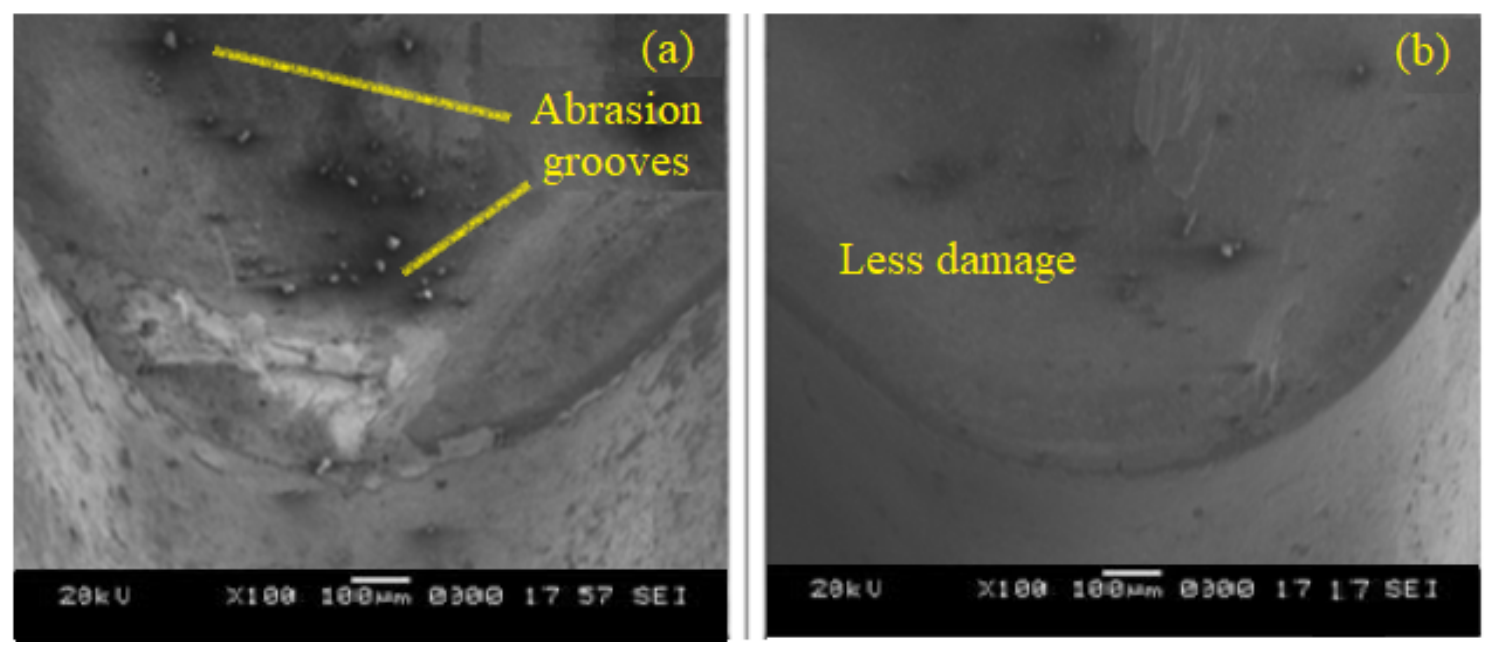

Figure 13. SEM morphology of cutting tool: (a) $2^{\text {nd }}$ orthogonal array (V1F1D1); (b) optimum machining condition based on TGRA (V3F1D1). 


\section{CONCLUSION}

The comparative study of indirect, direct, and hybrid cryogenic machining investigation is conducted in this work. The results clearly show improved machining characteristics for all the responses validated with analysis and justification. Finally, the TGRA approach is adopted to achieve the optimum machining condition validated with confirmative experiment. The cryogenic machining strategy has proven to be an environment friendly and work friendly machining approach as it does not have any ecological hazards. Moreover, there is no concern of leakage of coolant waste, as $\mathrm{LN}_{2}$ is dispersed in an atmosphere immediately after contact with a machining zone. It has also been found that, with use of $\mathrm{LN}_{2}$ as a coolant, there is no attempt required for disposal of the same. The key findings obtained from the study are discussed as follows:

- The ideal combination for cryogenic hard-turning machining attributes is obtained as follows: spindle speed of $110 \mathrm{~m} / \mathrm{min}$, cutting feed of $0.08 \mathrm{~mm} / \mathrm{rev}$, and depth of cut as $0.4 \mathrm{~mm}$.

- The feed rate has found to be the most crucial parameter, which influences the hard turning up to $48.33 \%$.

- The SEM and XRD analyses of cryo-treated tools show the formation of eta precipitates and finer grain distribution in the inserts, which improve their mechanical properties such as hardness and wear resistance.

- The nose wear in the indirect cryogenic environment reduced by $26.59 \%$ over direct cryogenic environment, whereas the cutting forces in the direct cryogenic environment reduced by $11.85 \%$ compared to the indirect cryogenic environment.

- On machining the Nimonic C 263 workpiece again with optimum combination of process parameters obtained from TGRA, the cutting force was found to be decreased from $188.3 \mathrm{~N}$ to $161.14 \mathrm{~N}$, and surface roughness reduced from $0.911 \mu \mathrm{m}$ to $0.837 \mu \mathrm{m}$, whereas nose wear reduced from $0.07 \mathrm{~mm}$ to $0.06 \mathrm{~mm}$.

\section{REFERENCES}

Antonialli, A.Í.S., Magri, A. and Diniz, A.E., 2016. Tool life and tool wear in taper turning of a nickel-based superalloy. The International Journal of Advanced Manufacturing Technology, 87(5):2023-32.

Aslantas, K., Ucun, I. and Cicek, A., 2012. Tool life and wear mechanism of coated and uncoated Al2O3/TiCN mixed ceramic tools in turning hardened alloy steel. Wear, 274:442-51.

Banh, T.L., Nguyen, H.P., Ngo, C. and Nguyen, D.T., 2018. Characteristics optimization of powder mixed electric discharge machining using titanium powder for die steel materials. Proceedings of the Institution of Mechanical Engineers, Part E: Journal of Process Mechanical Engineering, 232(3):281-98.

Batish, A., Bhattacharya, A., Kaur, M. and Cheema, M.S., 2014. Hard turning: Parametric optimization using genetic algorithm for rough/finish machining and study of surface morphology. Journal of Mechanical Science and Technology, 28(5):1629-40.

Behera, B.C., Alemayehu, H., Ghosh, S. and Rao, P.V., 2017. A comparative study of recent lubri-coolant strategies for turning of Ni-based superalloy. Journal of Manufacturing Processes, 30:541-52.

Behera, B.C., Ghosh, S. and Rao, P.V., 2016. Wear behavior of PVD TiN coated carbide inserts during machining of Nimonic 90 and Ti6Al4V superalloys under dry and MQL conditions. Ceramics International, 42(13):14873-85.

Chetan, Ghosh, S. and Rao, P.V., 2016. Environment friendly machining of Ni-Cr-Co based super alloy using different sustainable techniques. Materials and Manufacturing Processes, 31(7):852-59. 
Ghosh, S. and Rao, P.V., 2017. Performance evaluation of deep cryogenic processed carbide inserts during dry turning of Nimonic 90 aerospace grade alloy. Tribology international, 115:397-08.

Choudhury, I.A. and El-Baradie, M.A., 1998. Machinability of nickel-base super alloys: a general review. Journal of Materials Processing Technology, 77(1-3):278-84.

Degen, F., Klocke, F., Bergs, T. and Ganser, P., 2014. Comparison of rotational turning and hard turning regarding surface generation. Production Engineering, 8(3):309-17.

Selvam, M.D. and Sivaram, N., 2017. The effectiveness of various cutting fluids on the surface roughness of AISI 1045 steel during turning operation using minimum quantity lubrication system. Journal on Future Engineering \& Technology, 13(1):36-43.

Dhananchezian, M. and Kumar, M.P., 2011. Cryogenic turning of the Ti-6Al-4V alloy with modified cutting tool inserts. Cryogenics, 51(1):34-40.

Dogra, M., Sharma, V.S., Sachdeva, A., Suri, N.M. and Dureja, J.S., 2010. Tool wear, chip formation and workpiece surface issues in CBN hard turning: A review. International Journal of Precision Engineering and Manufacturing, 11(2):341-58.

Ezilarasan, C., Kumar, V.S., Velayudham, A. and Palanikumar, K., 2011. Surface roughness analysis on machining of nimonic $\mathrm{C}-263$ alloy using $\mathrm{ANN}$ and RSM techniques. International Journal of Precision Technology, 2(4):340-54.

Ezilarasan, C. and Velayudham, A., 2014. Theoretical predictions and experimental validations on machining the Nimonic C-263 super alloy. Simulation Modelling Practice and Theory, 40:192-07.

Ezilarasan, C. and Velayudham, A., 2013. An experimental analysis and measurement of process performances in machining of nimonic C-263 super alloy. Measurement, 46(1):185-99.

Ezilarasan, C. and Velayudham, A., 2013. Effect of machining parameters on surface integrity in machining Nimonic C-263 super alloy using whisker-reinforced ceramic insert. Journal of materials engineering and performance, 22(6):1619-28.

Ezugwu, E.O., Wang, Z.M. and Machado, A.R., 1999. The machinability of nickel-based alloys: a review. Journal of Materials Processing Technology, 86(1-3):1-16.

Gill, S.S., Singh, R., Singh, J. and Singh, H., 2012. Adaptive neuro-fuzzy inference system modeling of cryogenically treated AISI M2 HSS turning tool for estimation of flank wear. Expert Systems with Applications, 39(4):4171-80.

Goel, B., Singh, S. and Sarepaka, R.V., 2015. Optimizing single point diamond turning for mono-crystalline germanium using grey relational analysis. Materials and Manufacturing Processes, 30(8):1018-25.

Gupta, M.K., Sood, P.K., Singh, G. and Sharma, V.S., 2017. Sustainable machining of aerospace material-Ti (grade-2) alloy: modeling and optimization. Journal of cleaner production, 147:614-27.

Huu, P.N., Tien, L.B., Duc, Q.T., Van, D.P., Xuan, C.N., Van, T.N., Duc, L.N., Jamil, M. and Khan, A.M., 2019. Multi-objective optimization of process parameter in EDM using low-frequency vibration of workpiece assigned for SKD61. Sādhanā, 44(10):211.

Jadhav, P.S., Mohanty, C.P. and Shirguppikar, S.S., 2019. Cryogenic Treatment of Nimonic Alloy-Hard Turning: State-of-the-art, Challenges and Future Directions. Materials Today: Proceedings, 18: 4120-32.

Jadhav, P.S., Mohanty, C.P., Hotta, T.K. and Gupta, M., 2020. An optimal approach for improving the machinability of Nimonic C-263 superalloy during cryogenic assisted turning. Journal of Manufacturing Processes, 58: 693-05. 
Koyilada, B., Gangopadhyay, S. and Thakur, A., 2016. Comparative evaluation of machinability characteristics of Nimonic C-263 using CVD and PVD coated tools. Measurement, 85:152-63.

Lin, C.L., 2004. Use of the Taguchi method and grey relational analysis to optimize turning operations with multiple performance characteristics. Materials and manufacturing processes, 19(2):209-20.

Nguyen, H.P., Pham, V.D. and Ngo, N.V., 2018. Application of TOPSIS to Taguchi method for multicharacteristic optimization of electrical discharge machining with titanium powder mixed into dielectric fluid. The International Journal of Advanced Manufacturing Technology, 98(5-8):1179-98.

Nguyen, P.H., Banh, T.L., Mashood, K.A., Tran, D.Q. and Pham, V.D., 2020. Application of TGRA-Based Optimisation for Machinability of High-Chromium Tool Steel in the EDM Process. Arabian Journal for Science and Engineering,45(1):5555-62

Nguyen, H.P., Ngo, N.V. and Nguyen, Q.T., 2020. Optimizing process parameters in EDM using low frequency vibration for material removal rate and surface roughness. Journal of King Saud University Engineering Sciences: $1-8$

Özel, T., Hsu, T.K. and Zeren, E., 2005. Effects of cutting-edge geometry, workpiece hardness, feed rate and cutting speed on surface roughness and forces in finish turning of hardened AISI H13 steel. The International Journal of Advanced Manufacturing Technology, 25(3-4):262-69.

Özgün, Ö., Gülsoy, H.Ö., Findik, F. and Yilmaz, R., 2012. Microstructure and mechanical properties of injection moulded Nimonic-90 superalloy parts. Powder metallurgy, 55(5):405-14.

Patel, S.J., 2006. A century of discoveries, inventors, and new nickel alloys. Jom, 58(9):18-20.

Pawade, R.S., Joshi, S.S., Brahmankar, P.K. and Rahman, M., 2007. An investigation of cutting forces and surface damage in high-speed turning of Inconel 718. Journal of Materials Processing Technology, 192:13946.

Podder, B. and Paul, S., 2008. Effect of machining environment on machinability of Nimonic 263 during end milling with uncoated carbide tool. International Journal of Machining and Machinability of Materials, 3(12):104-19.

Podder, B. and Paul, S., 2012. Improvement of machinability in end milling of Nimonic C-263 by application of high-pressure coolant. International Journal of Machining and Machinability of Materials, 11(4):418-33.

Pusavec, F., Krajnik, P. and Kopac, J., 2010. Transitioning to sustainable production-Part I: application on machining technologies. Journal of Cleaner production, 18(2):174-84.

Ranganathan, S. and Senthilvelan, T., 2011. Multi-response optimization of machining parameters in hot turning using grey analysis. The International Journal of Advanced Manufacturing Technology, 56(5-8):45562.

Saini, S., Ahuja, I.S. and Sharma, V.S., 2012. Influence of cutting parameters on tool wear and surface roughness in hard turning of AISI H11 tool steel using ceramic tools. International Journal of Precision Engineering and Manufacturing, 13(8):1295-02.

Sarnobat, S.S. and Raval, H.K., 2019. Experimental investigation and analysis of the influence of tool edge geometry and work piece hardness on surface residual stresses, surface roughness and work-hardening in hard turning of AISI D2 steel. Measurement, 131:235-60.

Senthilkumar, N., Tamizharasan, T. and Anandakrishnan, V., 2014. Experimental investigation and performance analysis of cemented carbide inserts of different geometries using Taguchi based grey relational analysis. Measurement, 58:520-36. 
Sivaiah, P. and Chakradhar, D., 2017. Multi-objective optimisation of cryogenic turning process using Taguchibased grey relational analysis. International Journal of Machining and Machinability of Materials, 19(4): 297-12.

SreeramaReddy, T.V., Sornakumar, T., VenkataramaReddy, M. and Venkatram, R., 2009. Machinability of C45 steel with deep cryogenic treated tungsten carbide cutting tool inserts. International Journal of Refractory Metals and Hard Materials, 27(1):181-85.

Tang, L. and Du, Y.T., 2014. Multi-objective optimization of green electrical discharge machining Ti-6Al-4V in tap water via Grey-Taguchi method. Materials and Manufacturing Processes, 29(5):507-13.

Tebaldo, V., di Confiengo, G.G. and Faga, M.G., 2017. Sustainability in machining: "Eco-friendly" turning of Inconel 718. Surface characterisation and economic analysis. Journal of cleaner production, 140:1567-77.

Thakur, A., Gangopadhyay, S. and Maity, K.P., 2014. Effect of cutting speed and CVD multilayer coating on machinability of Inconel 825. Surface engineering, 30(7):516-23.

Thakur, A., Gangopadhyay, S. and Maity, K.P., 2014. Effect of cutting speed and tool coating on machined surface integrity of Ni-based super alloy. Procedia CIRP 14(1):541-45.

Thakur, D., Ramamoorthy, B. and Vijayaraghavan, L., 2008. Influence of different post treatments on tungsten carbide-cobalt inserts. Materials Letters, 62(28):4403-06. 